\title{
Combined effect of linolenic acid and tobramycin on Pseudomonas aeruginosa biofilm formation and quorum sensing
}

\author{
WARREN CHANDA $^{1 *}$, THOMSON PATRICK JOSEPH $^{1 *}$, ARSHAD AHMED PADHIAR $^{1}$, \\ XUEFANG GUO ${ }^{1}$, LIU MIN $^{1}$, WENDONG WANG ${ }^{1}$, SAINYUGU LOLOKOTE ${ }^{2}$, \\ ANHONG NING $^{3}$, JING CAO $^{3}$, MIN HUANG $^{1}$ and MINTAO ZHONG ${ }^{1}$
}

\author{
${ }^{1}$ Department of Microbiology, College of Basic Medical Sciences, Dalian Medical University; ${ }^{2}$ Department of \\ Epidemiology and Biostatistics, School of Public Health, Dalian Medical University; ${ }^{3}$ Laboratory of Pathogen Biology, \\ Experimental Teaching Center for Basic Medical Sciences, Dalian Medical University, Dalian, Liaoning 116044 P.R. China
}

Received April 6, 2017; Accepted August 22, 2017

DOI: $10.3892 / \mathrm{etm} .2017 .5110$

\begin{abstract}
Pseudomonas aeruginosa is a ubiquitous Gram negative opportunistic pathogen capable of causing severe nosocomial infections in humans, and tobramycin is currently used to treat $P$. aeruginosa associated lung infections. Quorum sensing regulates biofilm formation which allows the bacterium to result in fatal infections forcing clinicians to extensively use antibiotics to manage its infections leading to emerging multiple drug resistant strains. As a result, tobramycin is also becoming resistant. Despite extensive studies on drug discovery to alleviate microbial drug resistance, the continued microbial evolution has forced researchers to focus on screening various phytochemicals and dietary compounds for antimicrobial potential. Linolenic acid (LNA) is an essential fatty acid that possesses antimicrobial actions on various microorganisms. It was hypothesized that LNA may affect the formation of biofilm on P. aeruginosa and improve the potency of tobramycin. The present study demonstrated that LNA interfered with cell-to-cell communication and reduced virulence factor production. It further enhanced the potency of tobramycin and synergistically inhibited biofilm formation through $P$. aeruginosa quorum sensing systems. Therefore, LNA may be considered as a potential agent for adjunctive therapy and its utilization may decrease tobramycin concentration in combined treatment thereby reducing aminoglycoside adverse effects.
\end{abstract}

Correspondence to: Dr Mintao Zhong or Professor Min Huang, Department of Microbiology, College of Basic Medical Sciences, Dalian Medical University, 9 Western Section, Lvshun South Road, Lvshunkou, Dalian, Liaoning 116044, P.R. China

E-mail: dyzhongmt@163.com

E-mail: huangminchao@163.com

*Contributed equally

Key words: Pseudomonas aeruginosa, linolenic acid, biofilm, quorum sensing, tobramycin

\section{Introduction}

Pseudomonas aeruginosa (P.aeruginosa) is a ubiquitous Gram negative bacterium capable of surviving in several environmental niches such as mammals (including humans), insects, nematodes, soil, water and plants $(1,2)$. In humans, $P$. aeruginosa rarely causes community acquired pneumonia $(3,4)$, but has an increased incidence of causing hospital infections like hospital-acquired pneumonia, sepsis, urinary tract infections, and is prevalent among wound and burn patients $(1,5)$. The bacterium causes severe pulmonary damage and is a leading cause of mortality in cystic fibrosis patients (6-8). This opportunistic pathogen poses a huge challenge in clinical settings as compared to other pathogens because of its highly intrinsic resistance to most antibiotics including $\beta$-lactams, fluoroquinolones and aminoglycosides (9-11). Each year, the bacterium is estimated to cause 51,000 healthcare-associated infections out of which 6,000 cases are multidrug resistant with roughly 400 deaths occurring per year in the United States (9). In addition, P. aeruginosa has the ability to switch from free-living (planktonic) to biofilm phenotypic mode of living. This ability contributes to antibiotic resistance and is governed by quorum sensing systems that regulate virulence factor production as well $(1,12-14)$. Unlike other pathogens, $P$. aeruginosa has a unique virulence potential, its natural resistance to several antibiotics and other resistance mechanisms like antibiotic modification and energy-dependant drug efflux make infections very problematic to control $(15,16)$. Therefore, there is need to search for more compounds with antimicrobial potential to curb P. aeruginosa-related infections.

In the recent past, fatty acids (FA) have received attention because of their antimicrobial and anti-inflammatory properties $(17,18)$. They possess beneficial effects against cancerous cells, body fats, and in conditions such as depression, heart problems, neurodegenerative diseases, joint and bone conditions $(19,20)$. One of the widely discussed fatty acid family based on nutrition and human health benefits is the omega-3 family in which linolenic acid (C18:3n-3, LNA) is a parent fatty acid compound (21). Evidence has shown that LNA and its derivatives, eicosapentaenoic acid (EPA) and docosahexaenoic acid (DHA) possess antimicrobial properties against many 
microorganisms (22-26). Thus far, bacterial resistance towards free fatty acids is yet to be reported due to their broader spectrum activities (27). However, the last option of antimicrobial agents for multidrug resistant $P$. aeruginosa related infections include aminoglycosides and polymyxins, which besides losing their efficacy are also accompanied with side effects such as neurotoxicity, nephrotoxicity and ototoxicity (28-30). Nonetheless, these toxic side effects can be managed with reduced concentration and duration of tobramycin therapy. Besides, some studies have shown that phytochemical compounds can produce synergistic and additive effects with aminoglycosides in various bacterial infections thereby improving their (aminoglycosides) efficacious potential (31).

Despite several reports on the antibacterial activity of LNA and its omega-3 derivatives (EPA and DHA), the anti-biofilm mechanism and their interaction with aminoglycosides on $P$. aeruginosa pathogens have not been elucidated. Therefore, the present study aimed at assessing the anti-biofilm activity and mechanism of linolenic acid alone and in combination with tobramycin on $P$.aeruginosa, with the view to evaluating the potency of the compound alone or in combination for treating infections associated with this pathogen.

\section{Materials and methods}

Materials. Linolenic acid (Sigma-Aldrich), Azocasein (Sigma-Aldrich), AlarmaBlue cell viability assay kit (KeyGen BioTECH, China), Tobramycin (Solarbio, China), Crystal violet (Solarbio, China), LIVE/DEAD BacLight Bacterial viability kit (Molecular Probes, USA), Biozol Total RNA extraction reagent (BioFlux, China), TransScript Green Two-Step qRT-PCR SuperMix kit (Transgen Biotech, China), Trans2 K DNA ladder (Transgen Biotech, China), 2X Taq PCR MasterMix (TianGen, China), Ethidium bromide (Sigma, China), Cetrimide agar base (Xiya, China), Dimethyl sulfoxide (AMRESCO, Ohio-USA), and any other reagents were of analytical grade.

Bacterial strains. Pseudomonas aeruginosa ATCC 27853 strain, and Pseudomonas aeruginosa clinical strains were collected from the Laboratory of Pathogen Biology, Experimental Teaching Center for Basic Medical Sciences, Dalian Medical University while environmental strains were isolated from beach soil, water pond soil and garden soil in different locations on Dalian Medical University campus.

Primer design. The quantitative real time polymerase chain reaction (qRT-PCR) primers used in this study were designed with an online Primer-Blast tool (https:/www.ncbi.nlm.nih .gov/tools/primer-blast/; accessed March 11, 2016) whereas identification primers for $P$. aeruginosa were those published by Jaffe et al (32) (Table I) and all were synthesized by Invitrogen Biotechnology Co. Ltd, China.

Culture and identification of bacteria strains. Clinical isolates of $P$. aeruginosa and the ATCC strain were inoculated on cetrimide agar and incubated at $37^{\circ} \mathrm{C}$ for $24 \mathrm{~h}$. For environmental strains, $1 \mathrm{~g}$ of soil was dissolved in $1 \mathrm{ml} \mathrm{PBS}$, pH 7.4 with vigorous shaking and centrifuged at 5,000 $\mathrm{g}$ for one minute then $0.1 \mathrm{ml}$ was inoculated on cetrimide agar and incubated at $37^{\circ} \mathrm{C}$ for $24 \mathrm{~h}$. A bacterial suspension was prepared by dissolving a single colony from an overnight culture plate into $50 \mu 1$ PBS pH 7.4 from which, a) $30 \mu \mathrm{l}$ was added to a $15 \mathrm{ml}$-tube containing $3 \mathrm{ml}$ fresh LB media for overnight culture at $37^{\circ} \mathrm{C}$ with $180 \mathrm{rpm}$ shaking, then stored in $8 \%(\mathrm{v} / \mathrm{v})$ glycerol at $-80^{\circ} \mathrm{C}$ for use in subsequent assays; b) $1 \mu \mathrm{l}$ was used for identification with duplex colony polymerase chain reaction (PCR).

Duplex colony PCR. The PCR conditions were performed according to Jaffe et al (32) with modifications. Briefly, a $10 \mu 1$ reaction mixture was prepared to consist of $1 \mu \mathrm{l}$ bacteria suspension, $0.5 \mu \mathrm{M}$ forward and reverse primers apiece, $5 \mu \mathrm{l}$ of $2 \mathrm{X}$ Taq PCR MasterMix, 5\% Dimethyl sulfoxide (DMSO) and $1.5 \mu \mathrm{l}$ distilled water to bring the total volume to $10 \mu \mathrm{l}$. DMSO was included to improve primer binding specificity during amplification since Pseudomonas species have a high GC content. The thermal cycling conditions were set as follows: Initial denaturation at $94^{\circ} \mathrm{C}$ for $3 \mathrm{~min}$, a 30 cycle involving denaturation at $94^{\circ} \mathrm{C}$ for $30 \mathrm{sec}$, annealing at $58^{\circ} \mathrm{C}$ for $30 \mathrm{sec}$ and extension at $72^{\circ} \mathrm{C}$ for $30 \mathrm{sec}$, and a final extension at $72^{\circ} \mathrm{C}$ for $45 \mathrm{sec}$. After thermocycling, $10 \mu \mathrm{l}$ was then loaded into a $1 \%$ (w/v) agarose gel and the electrophoresis was run for $40 \mathrm{~min}$ at 70 volts in $1 \mathrm{X}$ Tris-acetate-EDTA (TAE) Buffer mixed with $0.2 \mathrm{mM}$ ethidium bromide, then the images were taken by ChemiDoc $\mathrm{XRS}^{+}$ machine (Bio-ad).

Minimum inhibition concentration determination. The minimum inhibition concentration (MIC) of linolenic acid (LNA) and tobramycin (TOB) were performed following CLSI recommendation using the macrodilution (Tube) broth method and broth microdilution method, respectively (33). The stock solution of LNA $(100 \mathrm{mg} / \mathrm{ml})$ was prepared in DMSO and a surfactant Tween 20 ( $2 \%$ final concentration) was added for the uniform distribution of LNA and two-fold serial dilutions were made. Firstly, an overnight $P$. aeruginosa culture was diluted to an optical density (OD) of 0.1 at $600 \mathrm{~nm}$ (Multiskan Ascent Microplate Reader, Thermo Scientific) with fresh LB broth $\left(\sim 10^{8} \mathrm{CFU} / \mathrm{ml}\right)$ and $10 \mu \mathrm{l}$ of bacteria suspension (to achieve a final bacterial concentration of $\sim 10^{6} \mathrm{CFU} / \mathrm{ml}$ ) was added to the test tubes containing $1 \mathrm{ml}$ media with serial dilutions of LNA, incubated at $37^{\circ} \mathrm{C}$ for $24 \mathrm{~h}$ with gentle shaking at $110 \mathrm{rpm}$. Similarly, a two-fold dilutions of TOB from $20 \mathrm{mg} / \mathrm{ml}$ to $0.0391 \mathrm{mg} / \mathrm{ml}$ were prepared in a 96 -well plate and incubated at $37^{\circ} \mathrm{C}$ for $24 \mathrm{~h}$. The highest dilution of LNA or TOB showing visible inhibition of bacterial growth after $24 \mathrm{~h}$ of incubation was taken as MIC of the drug. Three independent assays were performed.

Growth curve analysis. To understand the activity of LNA alone or in combination with TOB on the P. aeruginosa, sub-MIC concentrations of both LNA and TOB were selected for this study and were assessed through the growth curve analysis as described by Kalia et al (34). Briefly, overnight bacteria culture was inoculated into $10 \mathrm{ml}$ of LB broth supplemented with five different sub-MIC concentrations of LNA (i.e. 3/4, 5/8, 1/2, 3/8 and 1/4 of MIC) and TOB (1/4 of MIC). The flasks were incubated at $37^{\circ} \mathrm{C}$ and $\mathrm{OD}_{600}$ was monitored at time intervals $0,3,6,9,12,18$ and $24 \mathrm{~h}$.

Biofilm control assay. As described elsewhere (34,35), $P$. aeruginosa biofilm inhibition and biofilm metabolic 
Table I. Primer list for PCR and RT-qPCR.

\begin{tabular}{|c|c|c|c|c|}
\hline Target gene & Primer name & Sequence $\left(5^{\prime}-3^{\prime}\right)$ & Amplicon (bp) & (Refs.) \\
\hline oprL (PA0973) & $\begin{array}{l}\text { oprL-Forward } \\
\text { oprL-Reverse }\end{array}$ & $\begin{array}{l}\text { ATGGAA ATGCTGAAATTCGGC } \\
\text { CTTCTTCAGCTCGACGCGACG }\end{array}$ & 504 & (32) \\
\hline 16SrRNA & $\begin{array}{l}\text { 16SrRNA-Forward } \\
\text { 16SrRNA-Reverse }\end{array}$ & $\begin{array}{l}\text { GAGGAAGGTGGGGATGACGT } \\
\text { AGGCCCGGGAACGTATTCAC }\end{array}$ & 233 & (32) \\
\hline lasI (PA1432) & $\begin{array}{l}\text { LasI-Forward } \\
\text { LasI-Reverse }\end{array}$ & $\begin{array}{l}\text { TGAAGCCCAGGTTTTCGGTT } \\
\text { AACGGCTGAGTTCCCAGATG }\end{array}$ & 131 & This study \\
\hline lasR (PA1430) & $\begin{array}{l}\text { LasR-Forward } \\
\text { LasR-Reverse }\end{array}$ & $\begin{array}{l}\text { TCGAACATCCGGTCAGCAAA } \\
\text { GTTCACATTGGCTTCCGAGC }\end{array}$ & 128 & This study \\
\hline rhlI (PA3476) & $\begin{array}{l}\text { RhlI-Forward } \\
\text { RhlI-Reverse }\end{array}$ & $\begin{array}{l}\text { CATCCGCAAACCCGCTACAT } \\
\text { GGGTTTCGCTGCACAGGTA }\end{array}$ & 124 & This study \\
\hline rhlR (PA3477) & $\begin{array}{l}\text { RhlR-Forward } \\
\text { RhlR-Reverse }\end{array}$ & $\begin{array}{l}\text { GAAATGGTGGTCTGGAGCGA } \\
\text { GGAAAGCACGCTGAGCAAAT }\end{array}$ & 132 & This study \\
\hline pilJ (PA0411) & $\begin{array}{l}\text { pilJ-Forward } \\
\text { pilJ-Reverse }\end{array}$ & $\begin{array}{l}\text { GACAAGCAGTACATCGGCCA } \\
\text { CGTTTCTCGAAGTCGTTGCG }\end{array}$ & 137 & This study \\
\hline algU (PA0762) & $\begin{array}{l}\text { algU-Forward } \\
\text { algU-Reverse }\end{array}$ & $\begin{array}{l}\text { CCATCAACACCGCGAAGAAC } \\
\text { ATCTCATCCCGCAACATCGC }\end{array}$ & 148 & This study \\
\hline pqsH (PA2587) & $\begin{array}{l}\text { pqsH-Forward } \\
\text { pqsH-Reverse }\end{array}$ & $\begin{array}{l}\text { AGACGCTGATCCTGTTCCAG } \\
\text { GCGAACGAGGGTATTCCTCA }\end{array}$ & 131 & This study \\
\hline mvfR (PA1003) & $\begin{array}{l}\text { mvfR-Forward } \\
\text { mvfR-Reverse }\end{array}$ & $\begin{array}{l}\text { TCGTTCTGCGATACGGTGAG } \\
\text { CGTCGATGGTGATGGCGATA }\end{array}$ & 136 & This study \\
\hline oprF (PA1777) & $\begin{array}{l}\text { oprF-Forward } \\
\text { oprF-Reverse }\end{array}$ & $\begin{array}{l}\text { CAGTACCCGTCCACTTCCAC } \\
\text { TTCACGCGACCACCTTCTAC }\end{array}$ & 146 & This study \\
\hline oprI (PA2853) & $\begin{array}{l}\text { oprI-Forward } \\
\text { oprI-Reverse }\end{array}$ & $\begin{array}{l}\text { AGAAACCGAAGCTCGTCTGA } \\
\text { CGTTAGCCTCGTCAGCAGT }\end{array}$ & 137 & This study \\
\hline phzR/qscR (PA1898) & $\begin{array}{l}\text { phzR-Forward } \\
\text { phzR-Reverse }\end{array}$ & $\begin{array}{l}\text { GCTGACCGCGCCTAAATATC } \\
\text { TCCAGATCAGCGGGGTGTAT }\end{array}$ & 134 & This study \\
\hline lasB (PA3724) & $\begin{array}{l}\text { lasB-Forward } \\
\text { lasB-Reverse }\end{array}$ & $\begin{array}{l}\text { TGTCCAAACTCCCCAGCAAG } \\
\text { GAATTGCTCGTAGCGGGTGA }\end{array}$ & 149 & This study \\
\hline
\end{tabular}

activity quantification were assessed in the presence/absence of LNA, TOB or in combination (LNA+TOB). Briefly, one microliter of overnight bacteria suspension adjusted to $\mathrm{OD}_{600}$ of $0.1\left(\sim 10^{8} \mathrm{CFU} / \mathrm{ml}\right)$ was added to a well in a microtiter plate containing $100 \mu \mathrm{l}$ of fresh LB media mixed with appropriate doses of drugs, and this plate was incubated at $37^{\circ} \mathrm{C}$ for $24 \mathrm{~h}$ from which subsequent assays were performed as follows:

Biofilm mass quantification. After incubation, the unattached cells were gently aspirated and discarded, and the wells were washed with $0.85 \%$ sodium chloride (normal saline) twice and stained with $200 \mu \mathrm{l}$ of $0.1 \%$ crystal violet for $15 \mathrm{~min}$. The stain was discarded, and the wells were washed with distilled water, air dried and the dye was re-solubilized with $160 \mu \mathrm{l}$ of $33 \%(\mathrm{v} / \mathrm{v})$ glacial acetic acid (36). The OD was measured at $570 \mathrm{~nm}$ using Multiskan Ascent Microplate Reader (Thermo Scientific). Biofilm inhibition was given by:

$$
\% \mathrm{BI}=\left\{\left(\mathrm{OD}_{\mathrm{C}}-\mathrm{OD}_{\mathrm{T}}\right) / \mathrm{OD}_{\mathrm{C}}\right\} \times 100
$$

where $\% \mathrm{BI}$ is the percentage of biofilm inhibition, $\mathrm{OD}_{\mathrm{C}}$ is the $570 \mathrm{~nm}$ absorbance value of untreated sample and $\mathrm{OD}_{\mathrm{T}}$ is the $570 \mathrm{~nm}$ absorbance value of treated sample (35).
Biofilm metabolic activity quantification. In order to assess the bacterial activity of biofilm cells, the alamarblue (7-hydroxy-3H-phenoxazin-3-one-10-oxide) cell viability assay was applied as a commended, reliable and reproducible assay for assessing biofilm susceptibility $(35,37)$. After incubation as mentioned above, the supernatant was removed and the wells were gently washed twice with LB media. Then, $200 \mu 1$ fresh LB media containing $10 \%$ (v/v) alarmablue staining reagent was added and incubated at $37^{\circ} \mathrm{C}$ for $5 \mathrm{~h}$, as recommended by the manufacturer (KeyGen Biotech, China). The absorbance was then measured at $570 \mathrm{~nm}$ and Biofilm inactivation was given by:

$$
\% \mathrm{BI}=\left\{\left(\mathrm{A}_{\mathrm{C}}-\mathrm{A}_{\mathrm{T}}\right) / \mathrm{A}_{\mathrm{C}}\right\} \times 100 .
$$

where $\% \mathrm{BI}$ is the percentage of biofilm inactivation, $\mathrm{A}_{\mathrm{C}}$ is the $570 \mathrm{~nm}$ absorbance value of the untreated sample and $\mathrm{A}_{\mathrm{T}}$ is the $570 \mathrm{~nm}$ absorbance value of treated sample (35).

Microscopic analysis. To visualize the effect of biofilm formation in the presence/absence of sub-MIC doses of LNA, TOB or LNA+TOB, microscopic analysis of $P$. aeruginosa clinical strain $\mathrm{C} 2$ biofilms was performed as described previously $(11,38,39)$ with modifications. Briefly, $10 \mu \mathrm{l}$ of an 
overnight culture as described above, was added to $1 \mathrm{ml} \mathrm{LB}$ media supplemented with appropriate sub-MIC doses in a 24-well plate. Positive control wells contained media supplemented with the greatest concentration of DMSO used $(0.75 \%)$ while the negative control wells contained media only (for sterility check), and the plate was then incubated at $37^{\circ} \mathrm{C}$ for $24 \mathrm{~h}$. Afterwards, the wells were gently washed with sterile normal saline and $200 \mu \mathrm{l}$ of staining solution in LB media containing $2.09 \mu \mathrm{M}$ of Syto 9 and $12.5 \mu \mathrm{M}$ of Propidium iodide (PI) using LIVE/DEAD BacLight Bacterial Viability Kit L7012 was added to each well, incubated at room temperature for $15 \mathrm{~min}$ in the dark and images were captured with an inverted fluorescence microscope (Olympus IX71).

Synergy analysis. The interaction of LNA with TOB was analyzed by a checkerboard method in an $8 \times 8$ arrangement using a 96-well plate as previously described (24). Briefly, biofilms were allowed to build up for $24 \mathrm{~h}$ and then wells were gently washed with sterile LB medium and later supplemented with LB medium consisting of different combinations of LNA and TOB. The combinations were done in such a way that a fixed dose of one agent and increasing doses of the second agent was put in each column (or row). Then incubated at $37^{\circ} \mathrm{C}$ for $24 \mathrm{~h}$, washed gently and the biofilm metabolic activity was assessed with alamarblue staining reagent for assessing biofilm susceptibility $(35,37)$. For all the wells with combined drug concentrations, the sum of the fractional inhibitory concentrations (FIC) index was calculated according to the equation below:

$$
\mathrm{FIC} \text { index }=\mathrm{FIC}_{\mathrm{A}}+\mathrm{FIC}_{\mathrm{B}}=\mathrm{A} / \mathrm{MIC}_{\mathrm{A}}+\mathrm{B} / \mathrm{MIC}_{\mathrm{B}} \text {. }
$$

where A and B are the MICs of LNA (A) and TOB (B) in combination, $\mathrm{MIC}_{\mathrm{A}}$ and $\mathrm{MIC}_{\mathrm{B}}$ are the MICs of LNA and TOB alone, FIC $_{A}$ and FIC $_{B}$ are the FICs of LNA and TOB, respectively. The FIC index results were interpreted as synergistic effect (FIC index $\leq 0.5$ ), additive or indifferent effect (FIC index $>0.5$ and $\leq 1$ ) and antagonistic effect (FIC index >1) (40).

\section{Inhibition of virulence factors mediated by $Q S$}

Swarming assay. The swarming ability of $P$. aeruginosa $\mathrm{C} 2$ strain was investigated in small $35 \times 10 \mathrm{~mm}$ plates containing swarming motility media $0.5 \%(\mathrm{w} / \mathrm{v})$ Bacto agar, $0.5 \%(\mathrm{w} / \mathrm{v})$ peptone, $0.2 \%(\mathrm{w} / \mathrm{v})$ yeast extract and $1.0 \%(\mathrm{w} / \mathrm{v})$ glucose $(41)$. A $2.5 \mu \mathrm{l}$ aliquot from an overnight culture in the presence/absence of drug was spotted at the center of the agar surface and the plates were incubated at $37^{\circ} \mathrm{C}$ for $24 \mathrm{~h}$, and later $2 \mathrm{~h}$ at room temperature (42) and the diameters were measured. Three independent assays were performed.

Pyocyanin production. As described by Das et al (11) and Kalia et al (34), the pyocyanin production was assayed by collecting supernatants from overnight cultures of $P$. aeruginosa grown in the presence/absence of sub-MIC doses of LNA, TOB and LNA+TOB at $37^{\circ} \mathrm{C}$ for $24 \mathrm{~h}$. A $5 \mathrm{ml}$ culture supernatant was extracted with $3 \mathrm{ml}$ of chloroform and then with $1 \mathrm{ml}$ of $0.2 \mathrm{~N}$ hydrochloric acid to produce an orange-yellow to a pink colored solution which was measured at $520 \mathrm{~nm}$.
LasA staphylolytic assay. In the presence/absence of LNA, TOB and LNA+TOB drugs, the ability of $P$. aeruginosa culture supernatants to lyse boiled Staphylococcus aureus cells were determined by LasA protease activity (11). An overnight culture of $S$. aureus cells $\left(\mathrm{OD}_{595}\right.$ of 1.0$)$ was centrifuged at 7,000 rpm for $3 \mathrm{~min}$ and the pellet was suspended in $0.02 \mathrm{M}$ Tris- $\mathrm{HCl}(\mathrm{pH} 8.5)$ then boiled for $10 \mathrm{~min}$ and diluted with the same buffer to an $\mathrm{OD}_{595 \mathrm{~nm}}$ of 0.8. Diluted S. aureus suspension was added to each cell-free culture supernatant of $P$. aeruginosa in the ratio 9:1 and the absorbance was measured at $595 \mathrm{~nm}$ after $0,15,30,45$ and $60 \mathrm{~min}$.

Azocasein protease assay. The assay was performed to study the effect of protease production by $\mathrm{C} 2$ strain in the presence/absence of LNA, TOB and LNA+TOB. This was performed following methods published elsewhere with minor modifications $(11,34)$. Briefly, cell-free supernatant was collected from centrifuged overnight cultures in the presence/absence of drugs at $10,000 \mathrm{rpm}$ for $5 \mathrm{~min}$. $150 \mu \mathrm{l}$ of supernatant (in absence/presence of the drug) was added to $1 \mathrm{ml}$ of $0.3 \%$ azocasein in $0.05 \mathrm{M}$ Tris- $\mathrm{HCl}\left(\mathrm{pH} \mathrm{7.5)}\right.$ and incubated at $37^{\circ} \mathrm{C}$ for $15 \mathrm{~min}$. The reaction was then stopped with $0.5 \mathrm{ml} 10 \%$ trichloroacetic acid and the mixture was later centrifuged at $10,000 \mathrm{rpm}$ for 5 min. The clear supernatant was collected and absorbance was measured at $420 \mathrm{~nm}$.

Quantitative real-time polymerase chain reaction (qRT-PCR). The real-time PCR reactions for quantification of Pseudomonas aeruginosa quorum sensing target genes (lasI, lasR, rhlI, rhlR, ), virulence factor-related genes, and the reference gene (16S rRNA) were performed on ABI StepOne analyser using TransScript Green Two-Step qRT-PCR SuperMix kit following the manufacturer's instructions (Transgen Biotech, China) with the primers listed in Table I. Firstly, $P$. aeruginosa was cultured in the absence/presence of sub-MIC concentrations of LNA, TOB and LNA+TOB for $24 \mathrm{~h}$ at $37^{\circ} \mathrm{C}$. Total RNA was then extracted using biozol total RNA extraction reagent following the manufacturer's instructions (BioFlux, China) and the concentration was measured with NanoDrop 2000C (Thermo Scientific). One microgram of the respective extracted RNA was used for cDNA synthesis using TransScript Green Two-Step qRT-PCR SuperMix kit as per manufacturer's instructions. Secondly, the synthesized cDNA was diluted ten-fold $(1: 10$ ratio) and one microliter of diluted cDNA was mixed with $0.2 \mu \mathrm{M}$ forward and reverse primers apiece, $10 \mu 1$ of $2 \mathrm{X}$ TransStart Tip Green qPCR SuperMix, 1X passive reference dye I and water to a total volume of $20 \mu \mathrm{l}$ as per instructions. The dissociation stage consisted of $94^{\circ} \mathrm{C}$ for $30 \mathrm{sec}$, followed by 40 cycles involving $94^{\circ} \mathrm{C}$ for $5 \mathrm{sec}, 58^{\circ} \mathrm{C}$ for $15 \mathrm{sec}$, and $72^{\circ} \mathrm{C}$ for $10 \mathrm{sec}$. Target gene primers were designed to give products between 120 and $150 \mathrm{bp}$, and the 16SrRNA gene was used as an internal control. Each qRT-PCR run was performed in triplicate and three independent experiments were performed. The calculated threshold cycle $(\mathrm{Ct})$ was normalized to the $\mathrm{Ct}$ of $16 \mathrm{SrRNA}$ amplified from the corresponding sample. Finally, the relative quantification of target transcripts were calculated by the comparative $2^{-\Delta \Delta \mathrm{Ct}}$ method (43). 
Statistical analysis. To gain statistical significance, each experiment was performed at least in triplicate. Data values of experimental results were recorded as mean \pm SEM or median with interquartile range. Significance was determined by using analysis of variance (one- and two-way), and cited as $\mathrm{P}<0.05\left(^{*}\right), \mathrm{P}<0.01\left(^{* *}\right)$ and $\mathrm{P}<0.001\left(^{* * *}\right)$. Statistical analyses were performed using GraphPad Prism 5.0 statistical software.

\section{Results}

Antimicrobial and anti-biofilm effects of linolenic acid and tobramycin on Pseudomonas aeruginosa isolates. The present study examined five clinical strains, five environmental strains, and one standard (ATCC 27853) strain. The clinical and environmental strains were identified by duplex colony PCR using intragenic primer sets for bacterial $16 \mathrm{~S} r R N A$ and the peptidoglycan-associated lipoprotein (oprL: PA0973) gene sequences for specific detection of $P$. aeruginosa (data not shown).

Several reports suggest that FA of the omega-3 family are effective on various pathogenic microorganisms $(22,23,25,26,44)$. We therefore attempted to assess the antimicrobial activity of LNA on P. aeruginosa ATCC 27853, clinical and environmental strains. The median MIC values of LNA and TOB were 1.56 and $0.3125 \mathrm{mg} / \mathrm{ml}$, respectively. Due to this anti-pseudomonas activity, we hypothesized that LNA can affect biofilm formation when used alone or in combination with TOB. Therefore, five sub-MIC doses of LNA $(1.17,0.975,0.78,0.585 \& 0.39 \mathrm{mg} / \mathrm{ml})$, and $1 / 4$ th MIC $(0.078 \mathrm{mg} / \mathrm{ml})$ of TOB were selected for this study and their activity on planktonic cells were assessed through the growth curve analysis. The growth curve results showed nonsignificant results on planktonic cells (Fig. 1), but we went on to evaluate the anti-biofilm activities.

Interestingly, the ATCC strain was highly sensitive to TOB and LNA+TOB treatment in comparison with clinical and environmental stains (Fig. 2). An identical dose dependant pattern was exhibited in LNA+TOB and LNA groups with their respective highest median inhibitory percentage being 48 and 38\% (Fig. 2A). However, clinical strain C2 was noticed with extreme resistance to TOB dosage used while the rest of the strains were significantly affected $(\mathrm{P}<0.001$, Fig. 2B). The moderate inhibitory effect of LNA alone or in combination (Fig. 2A) provoked further analysis of biofilm cells. We attempted to assess the metabolic effect with alarmablue staining reagent to quantify the viability of cells (37). The assay revealed a significant inactivation of biofilm cells ( $\mathrm{P}<0.001$, Fig. 2C); 60\% inactivation with LNA+TOB involving $1.17 \mathrm{mg} / \mathrm{ml}$ dosage, $50 \%$ for LNA $(1.17 \mathrm{mg} / \mathrm{ml})$ alone and $42 \%$ for TOB alone (Fig. 2C). The slight difference between the two assays (inhibition and inactivated) was probably due to their different staining principles. Unlike alarmablue reagent, crystal violet staining does not differentiate live cells from dead cells but stains every attached biofilm cell whether live, about to die or dead ones, thus giving a slight difference between the two assays. After analyzing the inhibition and inactivation effects, $P$. aeruginosa clinical strain $\mathrm{C} 2$ was seen with more resistance especially with TOB (Fig. 2B and D). Therefore, we hypothesized that understanding the anti-biofilm action of LNA alone or in combination treatment could be better in a
Table II. Interaction study between LNA and TOB.

\begin{tabular}{|c|c|c|c|}
\hline $\begin{array}{l}\text { P. aeruginosa } \\
\text { strain }\end{array}$ & $\begin{array}{c}\text { Combined doses } \\
(\mathrm{LNA}+\mathrm{TOB})(\mathrm{mg} / \mathrm{ml})\end{array}$ & FIC index & Interpretation \\
\hline $\mathrm{C} 2$ & $1.17+0.078$ & 1.00 & Additive \\
\hline $\mathrm{C} 2$ & $0.78+0.078$ & 0.75 & Additive \\
\hline $\mathrm{C} 2$ & $0.39+0.078$ & 0.50 & Synergy \\
\hline
\end{tabular}

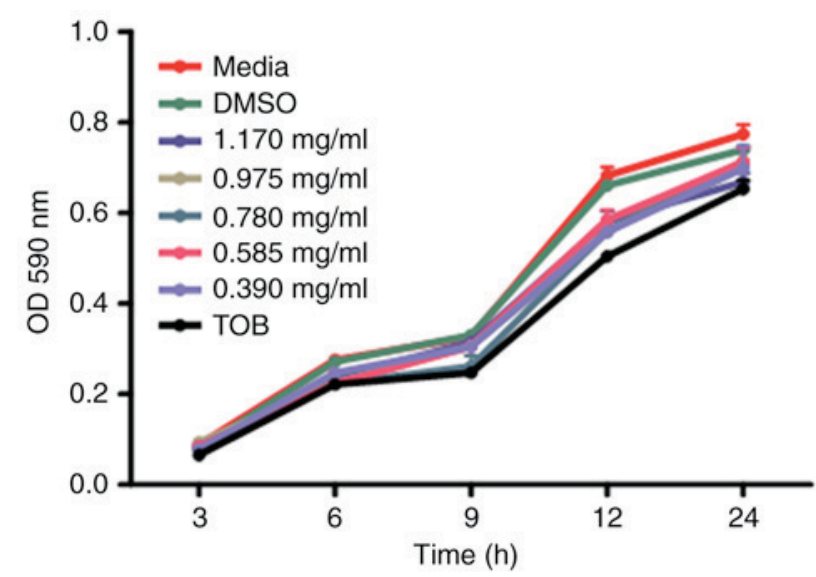

Figure 1. Growth curve evaluation with sub-MIC concentrations on Pseudomonas aeruginosa $\mathrm{C} 2$ strain. Media (positive control), DMSO (solvent control), sub-MIC doses of LNA (1.17-0.39 mg/ml), and TOB $(0.078 \mathrm{mg} / \mathrm{ml})$. Each value is an average of triplicate experiments where data are presented as mean \pm SEM and three independent assays were performed. TOB, tobramycin; LNA, linolenic acid.

strain where TOB is exerting an insignificant effect. Moreover, the ATCC strain very sensitive to the selected sub-MIC doses that further dilution was required to re-establish its MIC doses (data not shown). So, clinical strain C2 was selected for microscopic evaluation, virulence factor production and gene expression with qRT-PCR.

Microscopic visualization was performed with a fluorescence microscope (Olympus IX71). Images of the untreated control showed robust biofilm biomass but slightly reduced in TOB treated cells. LNA treated cells managed to reduce the biofilm formation by disintegrating the biomass while combination treatment exhibited strong inhibitory activity (Fig. 3). This effect reduced significantly in a dose-dependent manner in combined treatment groups. The findings here were in agreement with the biofilm inhibition (Fig. 2A) and inactivation (Fig. 2C) assays which also showed similar effects with reference to drug concentration used. Moreover, the interaction effect between LNA and TOB determined by the FIC index showed additive and synergistic effects on $\mathrm{C} 2$ strain (Table II), which could explain the strong attenuation effects of biofilm in combined treatment with reference to untreated control cells.

Effect of linolenic acid and tobramycin on virulence factor production. P. aeruginosa is known to produce virulence factors that include pyocyanin and protease production that tends to counteract host defenses and can directly damage 

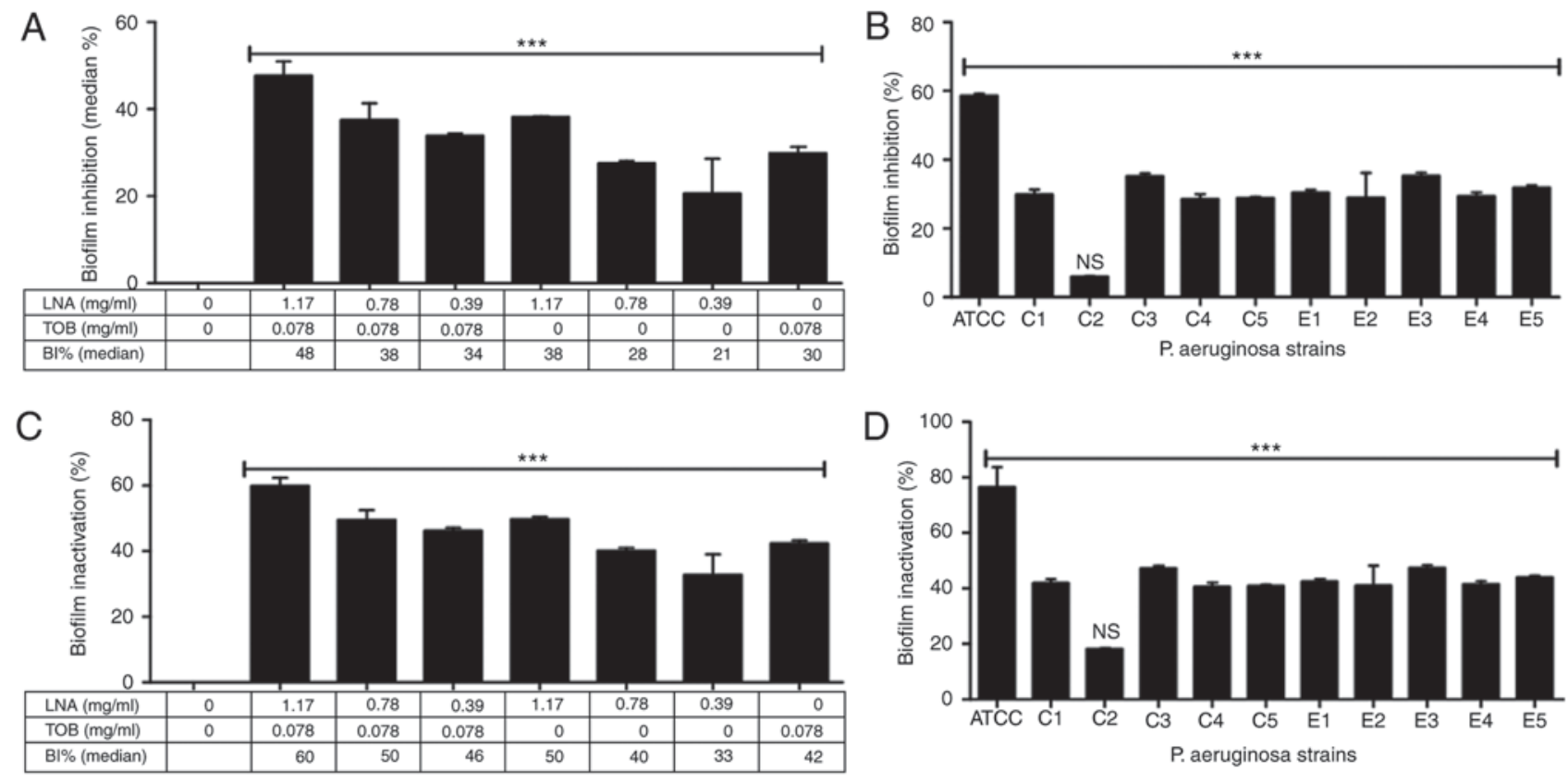

Figure 2. Biofilm inhibition and inactivation effects of linolenic acid, tobramycin, and LNA+TOB on P. aeruginosa strains. (A) Median inhibition percentages of all strains with respect to sub-MIC doses, (B) the inhibitory effect of TOB alone, (C) the median inactivation percentages of all strains with respect to sub-MIC doses, and (D) the inactivation effect of TOB alone are presented. The data are presented as median with interquartile ranges. LNA, linolenic acid; TOB, tobramycin; ATCC, ATCC 27853 strain; C, clinical strains; E, environmental strain; and ${ }^{* * *}$ P $<0.001$. Three independent assays were performed.
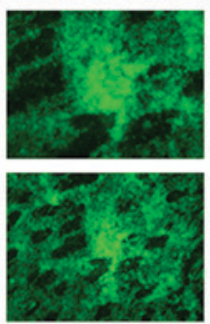

LNA 0

TOB 0
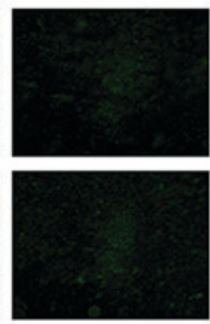

$1.17 \mathrm{mg} / \mathrm{ml}$

$0.078 \mathrm{mg} / \mathrm{ml}$
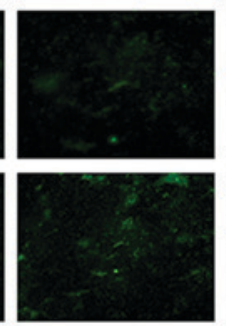

$0.78 \mathrm{mg} / \mathrm{ml}$

$0.078 \mathrm{mg} / \mathrm{ml}$
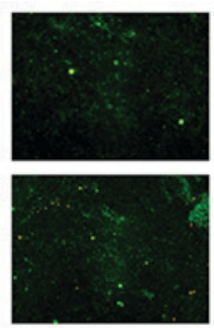

$0.39 \mathrm{mg} / \mathrm{ml}$

$0.078 \mathrm{mg} / \mathrm{ml}$
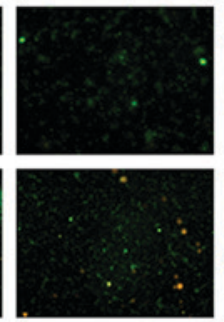

$1.17 \mathrm{mg} / \mathrm{ml}$

0
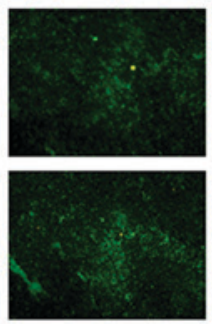

$0.78 \mathrm{mg} / \mathrm{ml}$

0

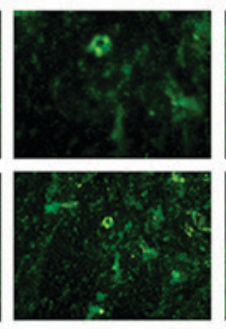

$0.39 \mathrm{mg} / \mathrm{ml}$ 0

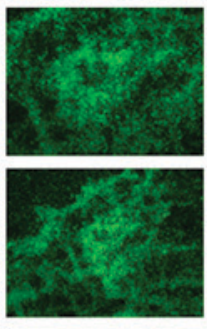

0

$0.078 \mathrm{mg} / \mathrm{ml}$

Figure 3. Effects of linolenic acid, tobramycin, and LNA+TOB on biofilm formation in a 24-well plate. Biofilm cells were stained with SYTO9/PI staining solution and images were captured with a fluorescence microscope (Olympus IX71). LNA, linolenic acid; TOB, tobramycin.

host tissues (45). Since virulence factor production and biofilm formation are controlled by the QS systems, we hypothesized that LNA alone or in combination with TOB can attenuate virulent factor production. So we assessed swarming motility, pyocyanin production, las A and azocasein activities on $P$. aeruginosa strain $\mathrm{C} 2$.

Swarming motility. Swarming motility is the ability of bacteria to move across a semisolid surface and $P$. aeruginosa uses a flagellar motility (42) and participates in increasing production of virulence factors and antibiotic resistance (46). We found that the treated group in comparison with the untreated control inhibited the swarming movement of $P$. aeruginosa C2 strain (Fig. 4). Interestingly, all the sub-MIC doses used in combination and single treatment showed significant inhibition effect on swarming motility with reference to the untreated control cells of $P$. aeruginosa $C 2$ strain $(\mathrm{P}<0.001$, Fig. 4).
Virulence factor production. P. aeruginosa virulence and pathogenesis include secretion of virulence factors such as pyocyanin and pyoverdine. Pyocyanin disrupts the redox system and electron transport pathways of a host cell whereas pyoverdine is a siderophore that captures iron usually from iron-binding proteins such as ferritin, lactoferrin, and transferrin $(45,47)$, and are important for virulence and biofilm formation (48). On the other hand, LasA protease possesses a high staphylolytic activity on cleaving the peptide bonds of pentaglycine bridges within the peptidoglycan of $S$. aureus cells and enhances the activity of LasB elastase in degrading the Gly-Gly peptide bonds in elastin, a component of connective tissue, blood vessels, and lung tissue (49). The effect of these virulence factors were examined in the presence/absence of sub-MIC doses of the drugs. The activity of LNA+TOB was more effective than single dose treatments (Fig. 5A-C). Therefore, combining the phenotypic findings and genotypic expression pattern, we presented the schematic diagram 
A

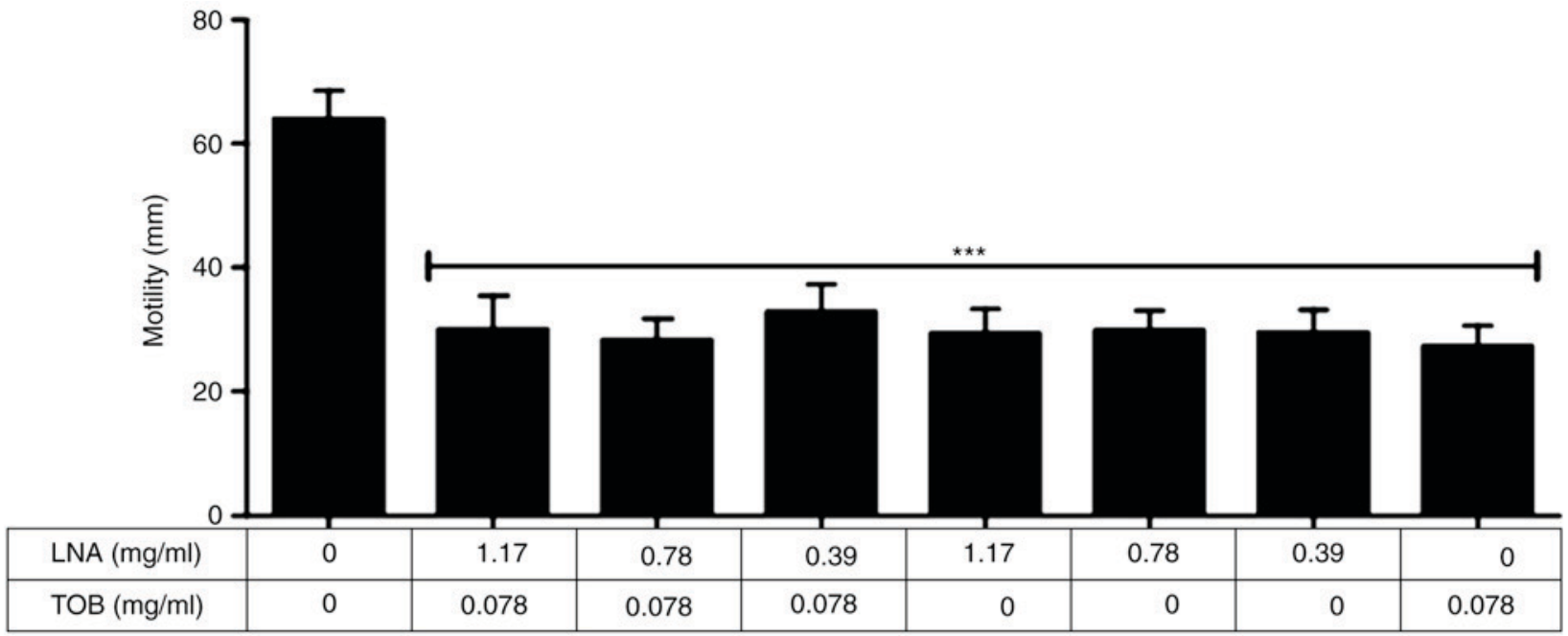

B

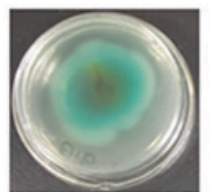

LNA 0

TOB 0

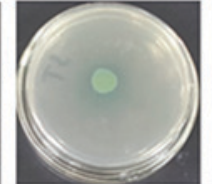

$1.17 \mathrm{mg} / \mathrm{ml}$

$0.078 \mathrm{mg} / \mathrm{ml}$

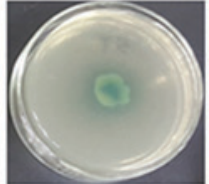

$0.78 \mathrm{mg} / \mathrm{ml}$

$0.078 \mathrm{mg} / \mathrm{ml}$

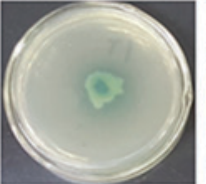

$0.39 \mathrm{mg} / \mathrm{ml}$

$0.078 \mathrm{mg} / \mathrm{ml}$

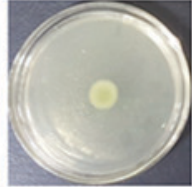

$1.17 \mathrm{mg} / \mathrm{ml}$

0

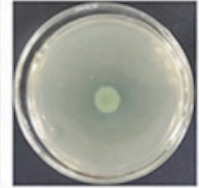

$0.78 \mathrm{mg} / \mathrm{ml}$

0

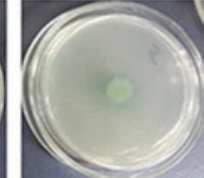

$0.39 \mathrm{mg} / \mathrm{ml}$

0

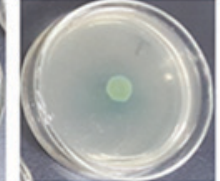

0

$0.078 \mathrm{mg} / \mathrm{ml}$

Figure 4. Effect of linolenic acid, tobramycin, and LNA+TOB on the swarming motility of Pseudomonas aeruginosa C2 strain. (A) Each value is an average of triplicate experiments where data are presented as mean \pm SEM. (B) One representative data set for three independent experiments is shown. Control, untreated; TOB, tobramycin; LNA, linolenic acid; ${ }^{* * *} \mathrm{P}<0.001$.

(Fig. 5D) illustrating the suggested targeted sites of LNA+TOB in the QS system.

The anti-biofilm mechanism of linolenic acid, tobramycin, and $L N A+T O B$ on $P$. aeruginosa $C 2$ strain. To analyze the effects of QS genes and virulence factor-related gene expressions by $P$. aeruginosa $\mathrm{C} 2$ strain in the presence/absence of sub-MIC doses of the drugs, quantitative real-time PCR (qRT-PCR) was performed to assess the relative expression of our target genes (lasI, lasR, rhlI, rhlR, pqsH, mvfR, oprF, oprI, pilJ, algU, $p h z R / q s c R$, and lasB). For this analysis, $0.39 \mathrm{mg} / \mathrm{ml}$ (LNA) and $0.078 \mathrm{mg} / \mathrm{ml}$ (TOB) were used in single and combined treatment on $\mathrm{C} 2$ strain because these concentrations exhibited synergism in the interaction study as shown by the FIC index (0.5; Table II).

Quantitative RT-PCR results showed nonsignificant effects of both LNA and TOB on QS genes but their expressions reduced by -91fold (lasI; PA1432), -20 fold (lasR; PA1430), -29 fold (rhll; PA3476) and -25 fold (rhlR; PA3477) due to LNA+TOB treatment $(\mathrm{P}<0.001$; Fig. 6A). These genes are the major regulators of Las system (lasI/lasR) and Rhl system (rhlI/rhlR). In spite of these two systems, the bacterium uses another system, the Pseudomonas quinolone signal system. For this system, the activated lasR expresses $m v f R$ that interacts with pqsABCDE loci to control the production of $p q s H$ and 2-heptyl-4-quinolone (HHQ), and the latter is converted into 2-heptyl-3-hydroxy-4-quinolone (PQS) by pqsH (50), as depicted in Fig. 5D. The product, PQS regulates various virulence factor related genes including elastase and pyocyanin coding genes (50). Also, evidence suggests that alterations in $m v f R$ expression disrupt PQS synthesis and pyocyanin production $(51,52)$. In addition, $m v f R$ mutant was shown to reduce virulence in an animal model (53). In the present study, we observed that the expression of $p q s H$ (PA2587; $\mathrm{P}<0.001)$ and $m v f R$ (PA1003; $\mathrm{P}<0.001)$ were downregulated by LNA+TOB whereas the cells treated with LNA or TOB showed no statistical significance (Fig. 6B). This suggested that LNA had no influence on the expression of our selected genes belonging to the three interrelated QS systems. However, due to the anti-biofilm effects that were exhibited in treatment groups (Fig. 2), we thought to assess the expression levels of oprI (PA2853), oprF (PA1777) and algU (PA0762) genes. OprF is an outer membrane protein that plays a role in maintaining the cell shape and contribute to $P$. aeruginosa virulence $(54,55)$. The counterpart outer membrane protein oprI also play a part in membrane integrity and normal cell shape (56). A study by Fito-Boncompte et al (55) reported that the absence of OprF disturbs bacterial cell adhesion to animal cells, release of ExoT and ExoS toxins through the type III secretion system (T3SS), and production of the QS-associated virulence factors such as lectin PA-1 L, elastase, pyocyanin, and exotoxin A. In addition, there was reduction and retardation in production of the signalling molecules 3oxoC12HSL and C4HSL respectively in the oprF mutant. In our study, LNA+TOB reduced the expression of $o p r F(\mathrm{P}<0.01)$ but not the outer membrane lipoprotein precursor $(o p r I)$ as compared to the untreated control (Fig. 6C). Moreover, alg $U$ is involved in regulating alginate production and inactivation of this gene increased the susceptibility of $P$. aeruginos PAO1 killing by chemically generated reactive oxygen species, J774 murine macrophages and human 

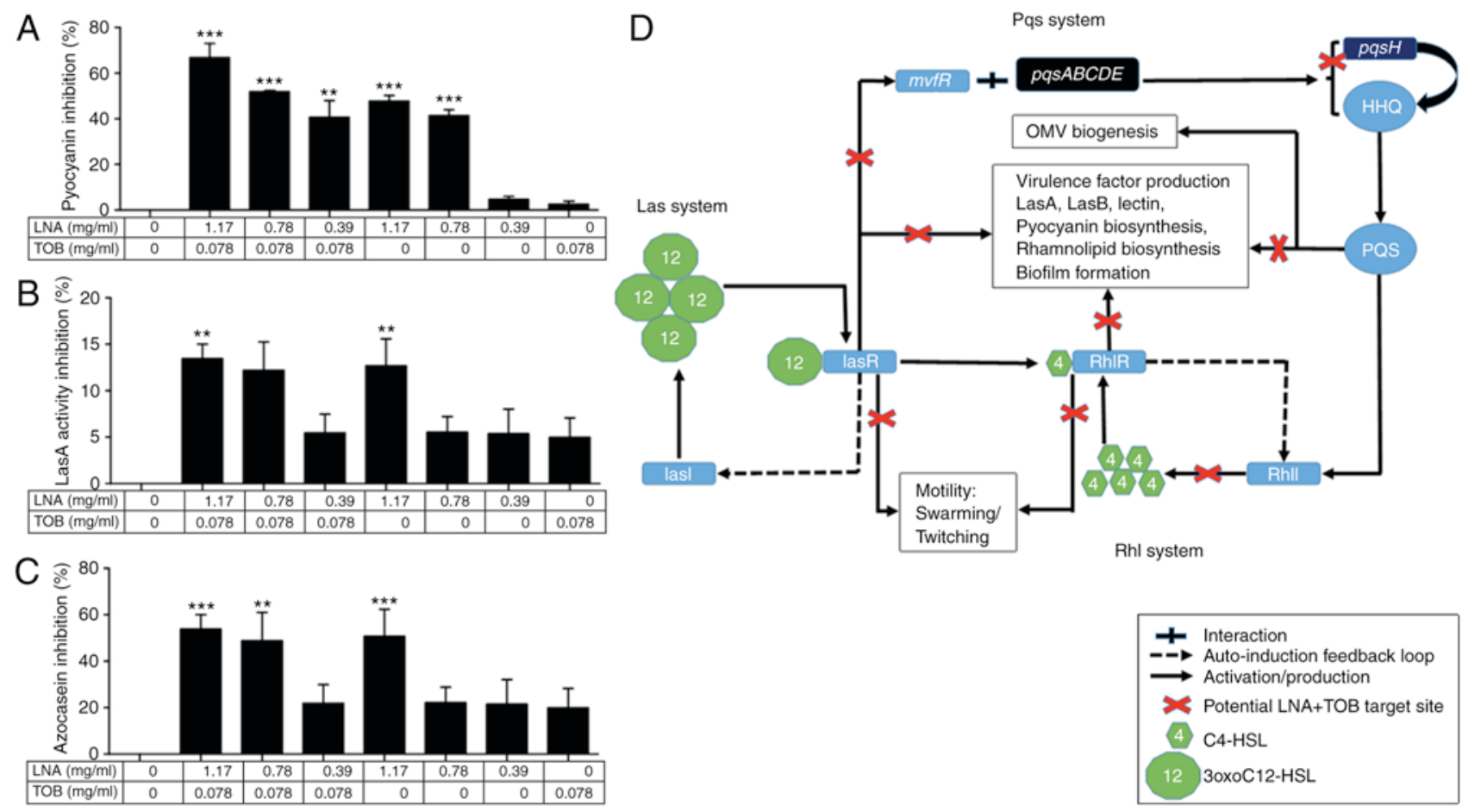

Rhl system

Figure 5. Effect of linolenic acid, tobramycin, and LNA+TOB on QS-regulated virulence factor production by Pseudomonas aeruginosa C2 strain. Percentage inhibition of (A) pyocyanin production, (B) LasA staphylolytic activity and (C) Azocasein protease production with respect to untreated control. (D) Schematic presentation of the activity of LNA+TOB on QS-regulated virulence factor production. Control, untreated cells; TOB, tobramycin; LNA, linolenic acid; ${ }^{* *} \mathrm{P}<0.01$ and ${ }^{* * * *} \mathrm{P}<0.001$ vs. untreated control. Three independent assays were performed.

neutrophils (57). Moreover, algU regulates $\operatorname{rsm} A$ expression, a posttranscriptional regulator involved in virulence factor production and biofilm formation (58). Interestingly, algU was downregulated by LNA+TOB $(\mathrm{P}<0.01)$ but upregulated in LNA or TOB treated groups with similar statistical magnitude (Fig. 6B). Furthermore, we selectively decided to assess the expression levels of pilJ (PA0411), phzR/qscR (PA1898) and las B (PA3724) that contribute to bacterial virulence. We observed the downregulation of pilJ (PA0411; $\mathrm{P}<0.001)$ and $p h z R / q s c R$ (PA1898; $\mathrm{P}<0.001)$ genes in LNA+TOB treated cells while LNA alone upregulated the pilJ $(\mathrm{P}<0.001)$ expression (Fig. 6C). Surprisingly, no statistically significant effect was noticed on las $B$ gene expression in all treatment groups as compared to the untreated control.

\section{Discussion}

Pseudomonas aeruginosa is a medically important pathogen that causes nosocomial and serious life threating infections due to its ability to produce biofilm that has contributed to the emergence of drug resistance towards currently utilized antibiotics. Considering the antimicrobial and anti-inflammatory properties of fatty acids $(17,18)$, assessing their biofilm prevention properties on $P$. aeruginosa may supplement in finding alternative agents for antimicrobial resistance problem. Moreover, evidence suggest that LNA and its derivatives, EPA and DHA possess antimicrobial properties against various pathogenic microorganisms (22-26).

Biofilm formation is an active process that is dependent highly on environmental signals which sensitize a cell to undergo stages of cycle growth. This process involves production of a matrix comprising of polysaccharides, proteins, lipids and extracellular DNA (eDNA) that provide a physiological barrier to antimicrobial diffusion and concentrate secreted extracellular enzymes such as $\beta$-lactamases, whereas the limitation of oxygen and nutrients support the anaerobic growth of $P$. aeruginosa which decelerates cell division $(2,10,59)$. During this stage, the bacterial community develops resistance to various antimicrobial agents, like $\beta$-lactam and aminoglycoside antibiotics that target actively and aerobically growing bacterial cells, respectively (59). Our study has shown that LNA, indeed possesses antibacterial and anti-biofilm effect against $P$. aeruginosa as evidenced by the MIC and biofilm inhibition/inactivation assays. We had observed that LNA alone and in combination with TOB had the ability to disrupt biofilm formation and decrease the metabolic activities of biofilm cells by causing cell death in a dose-dependent manner (Figs. 2 and 3). Besides, the stronger effects exhibited by the combined treatment suggested that LNA did not antagonize the activity of TOB but synergistically and additively exerted their combined effects on biofilm as supported by their FIC index results (Table II).

Furthermore, quorum sensing is a major player in $P$. aeruginosa virulence factor production and biofilm formation, making it an interesting target for an antipseudomonal compound search. Evidence has shown that inhibiting P. aeruginosa QS system disrupts biofilm formation and virulence factor production $(34,60)$. Our study showed that LNA+TOB had a great impact in downregulating the genes associated with the three interrelated QS systems (Las, Rhl and Pqs systems) (Fig. 6A and B). Since the bacterium uses QS systems to control biofilm formation and virulence factor secretion, attempts 

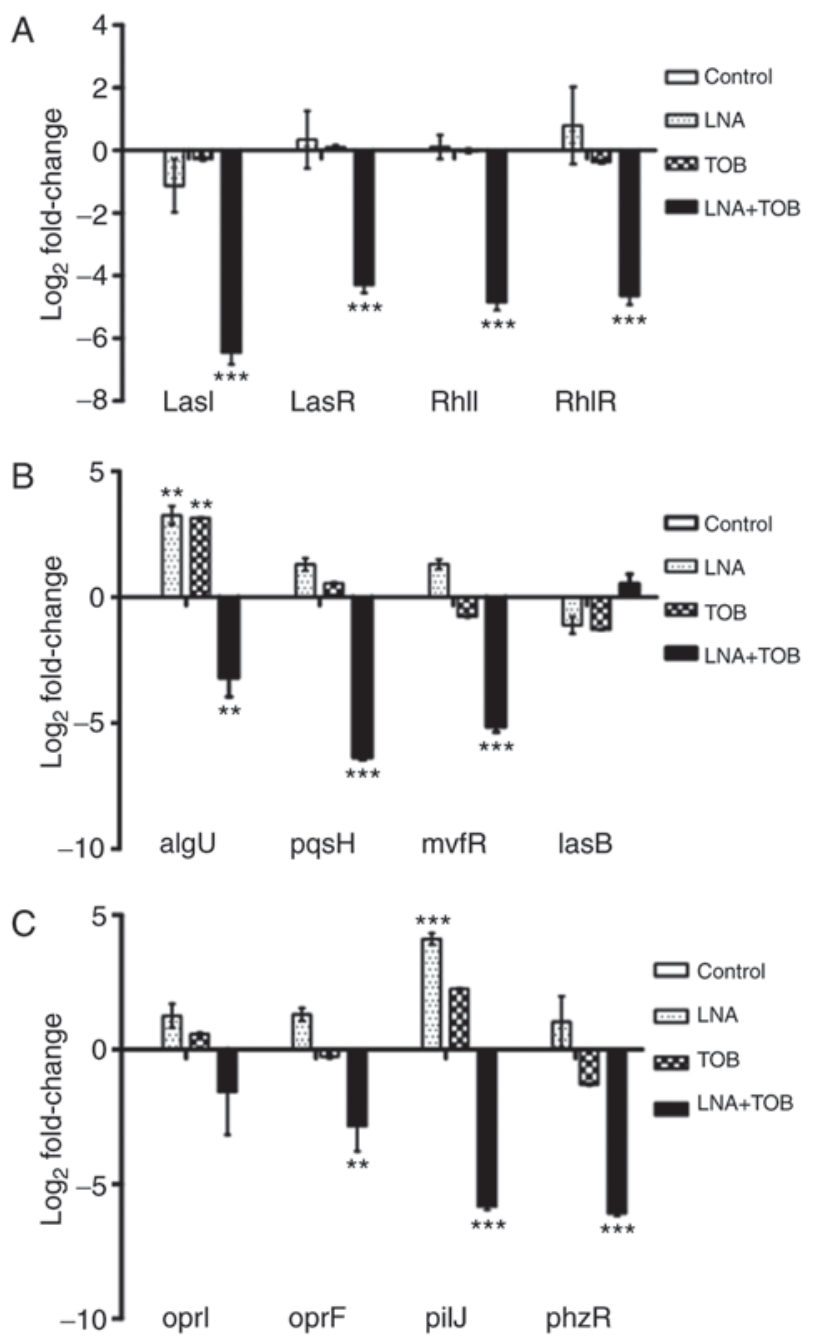

Figure 6. $\log 2$ fold change normalized quantification of QS- and virulence factor-related genes of Pseudomonas aeruginosa $\mathrm{C} 2$ strain of untreated and treated cells. (A) Key genes for Las and Rhl systems, (B) key genes for pqs system and virulence factor genes (algU and lasB genes) and (C) selected virulence factor genes. Each value is an average of triplicate experiment where data are presented as the mean \pm SEM. Target gene quantification was normalized to $16 \operatorname{Sr} R N A$ reference gene. ${ }^{* *} \mathrm{P}<0.01,{ }^{* * *} \mathrm{P}<0.001$ vs. untreated control. TOB, tobramycin; LNA, linolenic acid.

were made to analyze some virulence factor associated genes. $P$. aeruginosa produces outer membrane vesicles (OMV) as a tool for genetic information and toxins dissemination (61), and they require the signaling molecule $\mathrm{PQS}$ for their biogenesis which accumulates in the LPS-rich outer leaflet of the outer membrane and causes bleb formation (62). Previous evidence suggests that outer membrane proteins oprI and oprF participate in OMV formation but the absence of these proteins and presence of PQS still increased OMV production by P. aeruginosa (63). This implies that PQS play a major role in OMV biogenesis making it an attractive target for anti-biofilm exploration. We have shown that $\mathrm{LNA}+\mathrm{TOB}$ is capable of interfering with OMV biogenesis at gene transcription level (Fig. 6B and C). On the other hand, alginate is associated with chronic lung infection though only secreted by a subsection of $P$. aeruginosa species, as most strains can either secrete Psl (polysaccharide synthesis locus) or Pel (pectate lyase) polysaccharides $(64,65)$. Our study has shown that LNA+TOB is effective in disrupting alginate production (Fig. 6B). This suggests that LNA+TOB can be effective in reducing chronicity resulting from alginate production in lung infections. Moreover, we have shown that LNA+TOB treatment can prevent swarming and twitching motility thereby reducing the spread of infection. Therefore, we can deduce that LNA+TOB is more effective in preventing biofilm formation and virulence factor production than single LNA or TOB in targeting the QS system of $P$. aeruginosa. This could be due to the additive and synergistic effects that may occur once the two compounds are combined.

Although tobramycin is currently used in cystic fibrosis lung infections, it fails to clear chronic infection associated with $P$. aeruginosa completely (66). However, various compounds combined with tobramycin had shown synergism in attenuating biofilm formation by this pathogen $(67,68)$. Our study revealed that LNA can improved the efficacy of TOB and could be considered in P. aeruginosa related infections. In spite of the differences in the genotypic and phenotypic assays outcomes, it is no doubt that LNA is capable of reducing biofilm formation and virulence factor production as shown from our phenotypic analyses such as biofilm, swarming, phenazine, and proteases for being affected by LNA alone. However, the mechanism is definitely not associated with QS system but perhaps utilizing a different route to cause biofilm inhibition. For that, we hypothesized that LNA could be interacting with the cell membrane, increasing the membrane fluidity thereby disrupting its permeability causing the cell to leak out as well as transporting TOB in biofilm cells $(17,69)$, but substantialized analysis is needed. On the other hand, diet supplementation of omega-3 PUFA have been shown to improve the cardiovascular and respiratory conditions $(19,70)$, and was reported to be safe for human use (71), suggesting that LNA supplementation may serve as an immunomodulatory and antibiotic agent.

In conclusion, the present study demonstrates that linolenic acid has the capacity to interfere with $P$. aeruginosa biofilm formation and virulence factor production though experimented on the $\mathrm{C} 2$ strain. This strain exhibited stronger resistance to the selected doses than any other strain used in this study. It is therefore not acceptable to generalize the findings of one strain with the rest. However, it is imperative to note that these findings have shown the effectiveness of a combination therapy (LNA+TOB), which should stimulate critical analysis for antimicrobial consideration. Moreover, the combination therapy has shown strong synergism in disrupting the $P$. aeruginosa quorum sensing systems and decreasing its virulence factor production. Therefore, it can be deduced that linolenic acid used alone can attenuate the formation of biofilm and can improve the action of tobramycin in targeting the quorum sensing systems. This may decrease tobramycin concentration when in fact treated in combination with linolenic acid (in the form of dietary supplements) thereby reducing the adverse effects of aminoglycosides. However, this study is only based on in vitro investigations that may not mimic the clinical settings. Thus, the findings here may not be conclusive but stimulate interest in considering such compounds for adjunctive therapy. Hence more studies are required, especially in vivo studies with model systems that can simulate the clinical settings to substantiate our findings. 


\section{Acknowledgements}

We would like to convey our appreciation to Mr. Richardson Joseph (Ph.D. Fellow), Mr. Emeka Okoye (Ph.D. Fellow) and Dr. Brian Ayuka (MD) for reviewing this manuscript. We would like to also thank the Chinese Scholarship Council for their financial support.

\section{References}

1. Bai AJ and Rai VR: Quorum-Sensing Systems in Pseudomonas. In: Quorum Sensing vs Quorum Quenching: A Battle with No End in Sight. Kalia VC (ed). Springer India, pp73-84, 2015.

2. Sharma G, Rao S, Bansal A, Dang S, Gupta S and Gabrani R: Pseudomonas aeruginosa biofilm: Potential therapeutic targets. Biologicals 42: 1-7, 2014.

3. Takajo D, Iwaya K, Katsurada Y, Miyai K, Takasu A, Matsubara O, Sakamoto T, Tamai S and Tsuda H: Community-acquired lobar pneumonia caused by Pseudomonas aeruginosa infection in Japan: A case report with histological and immunohistochemical examination. Pathol Int 64: 224-230, 2014.

4. Gharabaghi MA, Abdollahi SM, Safavi E and Abtahi SH: Community acquired Pseudomonas pneumonia in an immune competent host. BMJ Case Rep 2012: pii: bcr0120125673, 2012.

5. Stryjewski M and Sexton D: Pseudomonas aeruginosa infections in specific types of patients and clinical settings. In: Severe infections caused by Pseudomonas aeruginosa. Hauser AR and Rello J (eds). Kluwer Academic Publishers, Boston, pp1-15, 2003.

6. Caron E, Desseyn JL, Sergent L, Bartke N, Husson MO, Duhamel A and Gottrand F: Impact of fish oils on the outcomes of a mouse model of acute Pseudomonas aeruginosa pulmonary infection. Br J Nutr 113: 191-199, 2015.

7. Kollef MH, Chastre J, Fagon JY, François B, Niederman MS, Rello J, Torres A, Vincent JL, Wunderink RG, Go KW and Rehm C: Global prospective epidemiologic and surveillance study of ventilator-associated pneumonia due to Pseudomonas aeruginosa. Crit Care Med 42: 2178-2187, 2014.

8. Bodey GP, Bolivar R, Fainstein V and Jadeja L: Infections caused by Pseudomonas aeruginosa. Rev Infect Dis 5: 279-313, 1983.

9. CDC: Antibiotic Resistance Threats in the United States, 2013. Journal 69-70, 2013.

10. Breidenstein EB, de la Fuente-Núñez C, Hancock RE: Pseudomonas aeruginosa: All roads lead to resistance. Trends Microbiol 19: 419-426, 2011.

11. Das MC, Sandhu P, Gupta P, Rudrapaul P, De UC, Tribedi P, Akhter Y and Bhattacharjee S: Attenuation of Pseudomonas aeruginosa biofilm formation by Vitexin: A combinatorial study with azithromycin and gentamicin. Sci Rep 6: 23347 , 2016.

12. Antunes LC, Ferreira RB, Buckner MM and Finlay BB: Quorum sensing in bacterial virulence. Microbiology 156: 2271-2282, 2010.

13. Juhas M,Eberl L and Tümmler B: Quorum sensing: The power of cooperation in the world of Pseudomonas. Environ Microbiol 7: 459-471, 2005.

14. Winzer K, Falconer C, Garber NC, Diggle SP, Camara M and Williams P: The Pseudomonas aeruginosa lectins PA-IL and PA-IIL are controlled by quorum sensing and by RpoS. J Bacteriol 182: 6401-6411, 2000.

15. Lyczak JB, Cannon CL and Pier GB: Establishment of Pseudomonas aeruginosa infection: Lessons from a versatile opportunist. Microbes Infect 2: 1051-1060, 2000.

16. Hancock RE and Speert DP: Antibiotic resistance in Pseudomonas aeruginosa: Mechanisms and impact on treatment. Drug Resist Updat 3: 247-255, 2000.

17. Desbois AP and Smith VJ: Antibacterial free fatty acids: Activities, mechanisms of action and biotechnological potential. Appl Microbiol Biotechnol 85: 1629-1642, 2010.

18. Desbois AP: Potential applications of antimicrobial fatty acids in medicine, agriculture and other industries. Recent Pat Antiinfect Drug Discov 7: 111-122, 2012.

19. Olveira G, Olveira C, Acosta E, Espíldora F, Garrido-Sánchez L, García-Escobar E, Rojo-Martínez G, Gonzalo M and Soriguer F: Fatty acid supplements improve respiratory, inflammatory and nutritional parameters in adults with cystic fibrosis. Arch Bronconeumol 46: 70-77, 2010 (In English, Spanish).
20. Nieuwenhove CPV, Terán V and González SN: Conjugated Linoleic and Linolenic Acid Production by Bacteria: Development of Functional Foods. In: Probiotics, Rigobelo EC (ed). INTECH, 2012.

21. WHO and FAO joint consultation: fats and oils in human nutrition. Nutr Rev 53: 202-205, 1995.

22. Sun M, Zhou Z, Dong J, Zhang J, Xia Y and Shu R: Antibacterial and antibiofilm activities of docosahexaenoic acid (DHA) and eicosapentaenoic acid (EPA) against periodontopathic bacteria. Microb Pathog 99: 196-203, 2016.

23. Correia M, Michel V, Matos AA, Carvalho P, Oliveira MJ, Ferreira RM, Dillies MA, Huerre M, Seruca R, Figueiredo C, et al: Docosahexaenoic acid inhibits Helicobacter pylori growth in vitro and mice gastric mucosa colonization. PLoS One 7: e35072, 2012.

24. Huang CB, George B and Ebersole JL: Antimicrobial activity of n- $6, n-7$ and n-9 fatty acids and their esters for oral microorganisms. Arch Oral Biol 55: 555-560, 2010.

25. Desbois AP and Lawlor KC: Antibacterial activity of long-chain polyunsaturated fatty acids against Propionibacterium acnes and Staphylococcus aureus. Mar Drugs 11: 4544-4557, 2013.

26. Mil-Homens D, Bernardes N and Fialho AM: The antibacterial properties of docosahexaenoic omega-3 fatty acid against the cystic fibrosis multiresistant pathogen Burkholderia cenocepacia. FEMS Microbiol Lett 328: 61-69, 2012.

27. Desbois AP, Mearns-Spragg A and Smith VJ: A fatty acid from the diatom Phaeodactylum tricornutum is antibacterial against diverse bacteria including multi-resistant Staphylococcus aureus (MRSA). Mar Biotechnol (NY) 11: 45-52, 2009.

28. Kaushik KS, Stolhandske J, Shindell O, Smyth HD and Gordon VD: Tobramycin and bicarbonate synergise to kill planktonic Pseudomonas aeruginosa, but antagonise to promote biofilm survival. NPJ Biofilms Microbiomes 2: 16006, 2016.

29. Zobell JT, Young DC, Waters CD, Ampofo K, Stockmann C, Sherwin CM and Spigarelli MG: Optimization of anti-pseudomonal antibiotics for cystic fibrosis pulmonary exacerbations: VI. Executive summary. Pediatr Pulmonol 48: 525-537, 2013.

30. Hirsch EB and Tam VH: Impact of multidrug-resistant Pseudomonas aeruginosa infection on patient outcomes. Expert Rev Pharmacoecon Outcomes Res 10: 441-451, 2010.

31. Morais-Braga MF, Souza TM, Santos KK, Guedes GM, Andrade JC, Tintino SR, Sobral-Souza CE, Costa JG, Saraiva AA and Coutinho HD: Phenolic compounds and interaction between aminoglycosides and natural products of Lygodium venustum SW against multiresistant bacteria. Chemotherapy 58: 337-340, 2012.

32. Jaffe RI, Lane JD and Bates CW: Real-time identification of Pseudomonas aeruginosa direct from clinical samples using a rapid extraction method and polymerase chain reaction (PCR). J Clin Lab Anal 15: 131-137, 2001.

33. CLSI: Methods for Dilution Antimicrobial Susceptibility Tests for Bacteria That Grow Aerobically; Approved Standard. 9th edition. CLSI document M07-A9 Vol 29: 17-19, 2012.

34. Kalia M, Yadav VK, Singh PK, Sharma D, Pandey H, Narvi SS and Agarwal V: Effect of cinnamon oil on quorum sensing-controlled virulence factors and biofilm formation in Pseudomonas aeruginosa. PLoS One 10: e0135495, 2015.

35. Borges A, Simões LC, Saavedra MJ and Simões M: The action of selected isothiocyanates on bacterial biofilm prevention and control. Int Biodeterior Biodegrad 86: 25-33, 2014.

36. Stepanovic S, Vukovic D, Dakic I, Savic B and Svabic-Vlahovic M: A modified microtiter-plate test for quantification of staphylococcal biofilm formation. J Microbiol Methods 40: 175-179, 2000.

37. Pettit RK, Weber CA and Pettit GR: Application of a high throughput Alamar blue biofilm susceptibility assay to Staphylococcus aureus biofilms. Ann Clin Microbiol Antimicrob 8: 28, 2009.

38. Musken M, Di Fiore S, Römling U and Häussler S: A 96-well-plate-based optical method for the quantitative and qualitative evaluation of Pseudomonas aeruginosa biofilm formation and its application to susceptibility testing. Nat Protoc 5: 1460-1469, 2010.

39. Johnson MB and Criss AK: Fluorescence microscopy methods for determining the viability of bacteria in association with mammalian cells. J Vis Exp, Sep 5, 2013. doi: 10.3791/50729. 
40. Konaté K, Mavoungou JF, Lepengué AN, Aworet-Samseny RR Hilou A, Souza A, Dicko MH and M'batchi B: Antibacterial activity against $\beta$-lactamase producing Methicillin and Ampicillin-resistants Staphylococcus aureus: Fractional inhibitory concentration index (FICI) determination. Ann Clin Microbiol Antimicrob 11: 18, 2012.

41. Krishnan T, Yin WF and Chan KG: Inhibition of quorum sensing-controlled virulencefactor production in Pseudomonas aeruginosa PAO1 by Ayurveda spice clove (Syzygium aromaticum) bud extract. Sensors (Basel) 12: 4016-4030, 2012.

42. Ha DG, Kuchma SL and O'Toole GA: Plate-based assay for swarming motility in Pseudomonas aeruginosa. Methods Mol Biol 1149: 67-72, 2014.

43. Schmittgen TD and Livak KJ: Analyzing real-time PCR data by the comparative C(T) method. Nat Protoc 3: 1101-1108, 2008.

44. Cheng CL, Huang SJ, Wu CL, Gong HY, Ken CF, Hu SY and Wu JL: Transgenic expression of omega-3 PUFA synthesis genes improves zebrafish survival during Vibrio vulnificus infection. J Biomed Sci 22: 103, 2015.

45. Gellatly SL and Hancock RE: Pseudomonas aeruginosa: New insights into pathogenesis and host defenses. Pathog Dis 67: 159-173, 2013

46. Overhage J, Bains M, Brazas MD and Hancock RE: Swarming of Pseudomonas aeruginosa is a complex adaptation leading to increased production of virulence factors and antibiotic resistance. J Bacteriol 190: 2671-2679, 2008.

47. Smith KD: Iron metabolism at the host pathogen interface: Lipocalin 2 and the pathogen-associated iroA gene cluster. Int J Biochem Cell Biol 39: 1776-1780, 2007.

48. Lamont IL, Konings AF and Reid DW: Iron acquisition by Pseudomonas aeruginosa in the lungs of patients with cystic fibrosis. Biometals 22: 53-60, 2009.

49. Andrejko M, Zdybicka-Barabas A, Janczarek $M$ and Cytryńska M: Three Pseudomonas aeruginosa strains with different protease profiles. Acta Biochim Pol 60: 83-90, 2013.

50. Diggle SP, Cornelis $\mathrm{P}$, Williams $\mathrm{P}$ and Cámara $\mathrm{M}$ : 4-quinolone signalling in Pseudomonas aeruginosa: Old molecules, new perspectives. Int J Med Microbiol 296: 83-91, 2006.

51. Gallagher LA, McKnight SL, Kuznetsova MS, Pesci EC and Manoil C: Functions required for extracellular quinolone signaling by Pseudomonas aeruginosa. J Bacteriol 184: 6472-6480, 2002.

52. Déziel E, Lépine F, Milot S, He J, Mindrinos MN, Tompkins RG and Rahme LG: Analysis of Pseudomonas aeruginosa 4-hydroxy-2-alkylquinolines (HAQs) reveals a role for 4-hydroxy-2-heptylquinoline in cell-to-cell communication. Proc Natl Acad Sci USA 101: 1339-1344, 2004.

53. Déziel E, Gopalan S, Tampakaki AP, Lépine F, Padfield KE, Saucier M, Xiao G and Rahme LG: The contribution of MvfR to Pseudomonas aeruginosa pathogenesis and quorum sensing circuitry regulation: Multiple quorum sensing-regulated genes are modulated without affecting lasRI, rhlRI or the production of N-acyl-L-homoserine lactones. Mol Microbiol 55: 998-1014, 2005.

54. Rawling EG, Brinkman FS and Hancock RE: Roles of the carboxy-terminal half of Pseudomonas aeruginosa major outer membrane protein OprF in cell shape, growth in low-osmolarity medium, and peptidoglycan association. J Bacteriol 180: 3556-3562, 1998.
55. Fito-Boncompte L, Chapalain A, Bouffartigues E, Chaker $\mathrm{H}$, Lesouhaitier O, Gicquel G, Bazire A, Madi A, Connil N, Véron W, et al: Full virulence of Pseudomonas aeruginosa requires OprF. Infect Immun 79: 1176-1186, 2011.

56. Lin YM, Wu SJ, Chang TW, Wang CF, Suen CS, Hwang MJ, Chang MD, Chen YT and Liao YD: Outer membrane protein I of Pseudomonas aeruginosa is a target of cationic antimicrobial peptide/protein. J Biol Chem 285: 8985-8994, 2010.

57. Yu H, Boucher JC, Hibler NS and Deretic V: Virulence properties of Pseudomonas aeruginosa lacking the extreme-stress sigma factor AlgU (sigmaE). Infect Immun 64: 2774-2781, 1996.

58. Stacey SD and Pritchett CL: Pseudomonas aeruginosa AlgU contributes to posttranscriptional activity by increasing rsma expression in a mucA22 strain. J Bacteriol 198: 1812-1826, 2016.

59. Prince AS: Biofilms, antimicrobial resistance, and airway infection. N Engl J Med 347: 1110-1111, 2002.

60. Kim HS, Lee SH, Byun Y and Park HD: 6-Gingerol reduces Pseudomonas aeruginosa biofilm formation and virulence via quorum sensing inhibition. Sci Rep 5: 8656, 2015.

61. Gujrati VB and Jon S: Bioengineered bacterial outer membrane vesicles: What is their potential in cancer therapy? Nanomedicine (Lond) 9: 933-935, 2014.

62. Schertzer JW and Whiteley M: A bilayer-couple model of bacterial outer membrane vesicle biogenesis. MBio 3: pii: e00297-11, 2012

63. Wessel AK, Liew J, Kwon T, Marcotte EM and Whiteley M: Role of Pseudomonas aeruginosa peptidoglycan-associated outer membrane proteins in vesicle formation. J Bacteriol 195: 213-219, 2013.

64. Ramsey DM and Wozniak DJ: Understanding the control of Pseudomonas aeruginosa alginate synthesis and the prospects for management of chronic infections in cystic fibrosis. Mol Microbiol 56: 309-322, 2005

65. Franklin MJ, Nivens DE, Weadge JT and Howell PL: Biosynthesis of the Pseudomonas aeruginosa Extracellular Polysaccharides, Alginate, Pel, and Psl. Front Microbiol 2: 167, 2011.

66. Price KE, Orazi G, Ruoff KL, Hebert WP, O'Toole GA and Mastoridis P: Mannitol does not enhance tobramycin killing of Pseudomonas aeruginosa in a cystic fibrosis model system of biofilm formation. PLoS One 10: e0141192, 2015.

67. Furiga A, Lajoie B, El Hage S, Baziard G and Roques C: Impairment of Pseudomonas aeruginosa biofilm resistance to antibiotics by combining the drugs with a new quorum-sensing inhibitor. Antimicrob Agents Chemother 60: 1676-1686, 2015.

68. Anderson GG, Kenney TF, Macleod DL, Henig NR and O'Toole GA: Eradication of Pseudomonas aeruginosa biofilms on cultured airway cells by a fosfomycin/tobramycin antibiotic combination. Pathog Dis 67: 39-45, 2013.

69. Lawrence GD: The Fats of Life: Essential Fatty Acids in Health and Disease. Rutgers University Press, 2010.

70. Pontes-Arruda A, Martins LF, de Lima SM, Isola AM, Toledo D, Rezende E, Maia M and Magnan GB; Investigating Nutritional Therapy with EPA, GLA and Antioxidants Role in Sepsis Treatment (INTERSEPT) Study Group: Enteral nutrition with eicosapentaenoic acid, $\gamma$-linolenic acid and antioxidants in the early treatment of sepsis: Results from a multicenter, prospective, randomized, double-blinded, controlled study: The INTERSEPT study. Crit Care 15: R144, 2011.

71. Chen W, Jiang H, Zhou ZY, Tao YX, Cai B, Liu J, Yang H, Lu CD and Zeng J: Is omega-3 fatty acids enriched nutrition support safe for critical ill patients? A systematic review and meta-analysis. Nutrients 6: 2148-2164, 2014. 